\title{
Model Kelembagaan Pengelolaan DAS Aesesa Flores, Provinsi NTT
}

\author{
Nicolaus Noywuli ${ }^{1}$, Asep Sapei², Nora H. Pandjaitan², dan Eriyatno ${ }^{3}$ \\ 1Program Doktor Ilmu PSL, Institut Pertanian Bogor; e-mail: nicolausnoywuli@gmail.com and psl@ipb.ac.id \\ 2 Departemen Teknik Sipil dan Lingkungan, Institut Pertanian Bogor \\ ${ }^{3}$ Pusat Studi Pembangunan Pertanian dan Pedesaan, Institut Pertanian Bogor
}

\begin{abstract}
ABSTRAK
Pengelolaan DAS Aesesa Flores di Provinsi Nusa Tenggara Timur menjadi penting dan prioritas karena isu daerah kepulauan, kesulitan mendapatkan air bersih, ketersediaan pangan dan kemiskinan, serta keterbelakangan pembangunan. Keberhasilan pengelolaan DAS yang berkelanjutan sangat ditentukan oleh kinerja kelembagaannya. Penelitian yang dilaksanakan pada bulan April-Mei 2018 ini bertujuan untuk menganalisis peran kelembagaan ditinjau dari aspek kendala, kebutuhan program dan actor/lembaga yang berperan dalam pengelolaan DAS Aesesa Flores. Data yang digunakan adalah data primer dan sekunder, khusus data primer diperoleh dari 7 (tujuh) orang pakar melalui pengisian kuesioner. Metode analisis data menggunakan pendekatan ISM (Interpretative Strutural Modelling) untuk menentukan factor kunci yang paling berperan dalam pengelolaan region hulu, tengah, dan hilir DAS Aesesa Flores. Hasilnya bahwa pengelolaan DAS AF yang berkelanjutan masih menghadapi 9 kendala pokok, membutuhkan 11 program, terdapat 5 aktor utama yang berperan dalam pengelolaan DAS AF yakni BPDAS Benain Noelmina, Forum DAS NTT, BWS NTT2, Masyarakat dan LSM. Pengelolaan DAS AF masih bersifat eksploitasi, belum mengarah pada pembangunan berkelanjutan dan tidak didukung dengan kelembagaan yang mumpuni sehingga diperlukan segera upaya untuk mengatasi kendala, implementasi program pokok, dan peningkatan peran dan kordinasi actor/pelaku pengelolaan DAS AF yang berkelanjutan.
\end{abstract}

Kata kunci: DAS Aesesa Flores, Interpetative Structural Modelling, Kelembagaan PDAS.

\begin{abstract}
The management on the Aesesa Flores (AF) watershed is important, particularly because of the imminent issues of clean water needs, food securities and a poverty rate of the local communities. The success of this management is influenced by the institution and governance in the AF watershed. This study was done from April to May 2018, and the main objective of the study is to determine the key factors that related to the AF watershed management. There were three main elements that were analyzed in this study, namely: (1) the key actors; (2) the key requirements; and (3) the key hindrances that influencing the AF watershed management. This study was using Interpretative Structural Modeling (ISM) to determine the key factors in each element. The data was collected primarily from an in-depth interview with 7 experts in the field of watershed management. The results from this study showed that there were 5 key actors that have the main influence in the AF watershed management, which are: (1) BPDAS (Governmental Watershed Institution); (2) Forum DAS (community forum of AF watershed); (3) BWS NTT2 (Regional River Management Institution); (4) Local communities; and (5) NGO (Non-Government Organization). The results from this study also suggested that the AF watershed management was explorative, thus may lead to unsustainable natural resources usage. Therefore, this study suggested that in order to achieve a sustainable watershed and natural resources usage, the relevant actors need to collaborate together to create a balance action plan that protects the environment, promoting economic growth and social affluence.
\end{abstract}

Keywords: Aesesa Flores watershed, Interpetative Structural Modelling, watershed institution and governance

Sitasi: Noywuli, N., Sapei, A., Pandjaitan, N.H dan Eriyatno (2018). Model Kelembagaan Pengelolaan DAS Aesesa Flores, Provinsi NTT. Jurnal Ilmu Lingkungan, 16(2),136-146, doi.org/10.14710/jil.16.2.136-146

\section{Pendahuluan}

Daerah aliran sungai sebagai suatu wilayah daratan yang secara topografi dibatasi oleh punggungpunggung gunung yang menampung dan menyimpan air hujan untuk kemudian menyalurkannya ke laut melalui sungai utama (Asdak 2010; Bisri 2019; PP. 37/2012). Chow et al., (1988), mengemukakan bahwa DAS dapat dipandang sebagai suatu sistem hidrologi dimana curah hujan merupakan input dari aliran sungai serta evapotranspirasi adalah output sistem. Lebih jauh dikemukakan bahwa DAS merupakan tempat terjadinya proses-proses yang berangkaian dan menjadi bagian dari siklus 
hidrologi. DAS secara umum dibagi menjadi daerah hulu dan hilir.

Secara biogeofisik, daerah hulu DAS dicirikan oleh hal-hal sebagai berikut: merupakan daerah konservasi, mempunyai kerapatan drainase lebih tinggi, merupakan daerah dengan kemiringan lereng besar (lebih besar dari 15\%), bukan merupakan daerah banjir, pengaturan pemakaian air ditentukan oleh pola drainase, dan jenis vegetasi umumnya merupakan tegakan. Sementara daerah hilir DAS dicirikan oleh hal-hal sebagai berikut: merupakan daerah pemanfaatan, kerapatan drainase lebih kecil, merupakan daerah dengan kemiringan lereng kecil sampai dengan sangat kecil (kurang dari $8 \%$ ), pada beberapa tempat merupakan daerah banjir, pengaturan pemakaian air ditentukan oleh bangunan irigasi, dan jenis vegetasi didominasi tanaman pertanian kecuali daerah estuaria yang didominasi hutan bakau/gambut (Asdak 2010).

Pengelolaan DAS menjadi sangat penting, mengingat fungsi DAS, baik sebagai pengendali dan penyimpan air baku, area pengembangan wilayah, hingga berbagai aktivitas ekonomi berbasis sumberdaya alam, serta banyak sektor yang terkait didalamnya, seperti; kehutanan, pertanian, perkebunan, pengairan, PDAM, dan sektor-sektor jasa dan publik lainnya, menjadikan wilayah DAS menjadi sangat vital dan strategis. Oleh karena itu pengelolaan DAS yang integrate, komprehensif dan berkelanjutan baik biofisik maupun social ekonomi dan kelembagaannya (UU 41/1999; UU 32/2009; Hariadi at al 2004).

Permasalahan kelembagaan dalam pengelolaan Daerah Aliran Sungai (DAS) Aesesa Flores (AF) memiliki karakteristik yang kompleks. Oleh sebab itu pendekatan yang tepat digunakan untuk menyelesaikan masalah tersebut adalah dengan pendekatan kesisteman (Eriyatno dan Sofyar, 2007). Kelembagaan pengelola DAS AF sangat diperlukan guna melaksanakan pengelolaan secara benar, efisien dan efektif (Isnugroho, 2001).

Untuk perencanaan strategis yang melibatkan keterkaitan yang luas dan beragam dari berbagai lembaga, analisis yang tepat menggunakan metode Interpretation Structural Modeling (ISM) (Saxena, 1992 dalam Eriyatno, 1999). Selanjutnya dikatakan bahwa metode ISM berkaitan dengan interpretasi suatu objek utuh atau perwakilan dari suatu sistem melalui aplikasi teori grafis secara sistematika dan berulang-ulang. Metode ini dibagi menjadi dua bagian yaitu penyusunan hierarki dan klasifikasi sub elemen. Prinsip dasarnya adalah identifikasi dari struktur di dalam sistem secara efektif untuk mengambil keputusan yang lebih baik. Dalam melakukan analisis, elemen-elemen yang digunakan adalah elemen yang dominan yang dikonsultasikan dengan pakar yakni elemen kendala, kebutuhan program dan actor atau lembaga (Noywuli et al 2017; Surya 2015; Suwarno 2011).

Kelembagaan dapat berarti bentuk atau wadah atau organisasi sekaligus juga mengandung pengertian tentang norma-norma, aturan, dan tata cara atau prosedur yang mengatur hubungan antar manusia, bahkan kelembagaan merupakan sistem yang kompleks, rumit dan abstrak (Kartodiharjo at al 2004). Karena itu perlu dianalisis mengenai kendala, kebutuhan dan kelembagaan dalam pengelolaan DAS AF yang berkelanjutan.

Pengelolaan DAS AF sedianya menjadi kewenangan Pemerintah Propinsi NTT dan BDAS Benain Noemina, namun karena kerberadaanya di antara Kabupaten Ngada dan Nagekeo di Pulau Flores, maka perlu dikaji aspek kendala, kebutuhan dan kelembagaan yang berperan dalam pengelolaannya. Kajian ini menggunakan metode Interpretative Structural Modelling (ISM) dengan menggunakan instrumen kuesioner dan diskusi pakar. Teknik Interpretatif Structural Modelling (ISM) ini digunakan untuk merumuskan alternatif kebijakan dimasa yang akan datang. Penelitian terdahulu oleh Nuddin et al. (2007) telah menggunakan ISM untuk mengidentifikasi lembagalembaga utama yang berperan penting di dalam perencanaan pengelolaan DAS Bila, Provinsi Sulawesi Selatan.

Analisis ini digunakan sebagai salah satu alat (tool) dalam penelitian ini. Dengan analisis ISM ini ingin diketahui faktor kunci apa saja yang berperan dalam pengelolaan DAS AF yang berkelanjutan. Oleh karena itu, penentuan faktor kunci tersebut adalah penting, dan sepenuhnya harus merupakan pendapat dari pihak yang berkompeten sebagai pakar (expert). Penelitian bertujuan untuk: (1) menganalisis peran kelembagaan ditinjau dari aspek kendala yang dihadapi, kebutuhan program terkait, dan lembaga atau aktor yang berperan dalam pengelolaan berkelanjutan DAS AF; dan (2) mengembangkan model kelembagaan pengelolaan berkelanjutan DAS AF dengan metode Interpretative Structural Modelling (ISM).

\section{Metodologi}

\subsection{Jenis dan Sumber Data}

Jenis data yang dikumpulkan dalam kajian model kelembagaan pengelolaan DAS-AF, adalah data sekunder dan data primer. Data sekunder diperoleh melalui penelusuran literature hasil-hasil penelitian, studi pustaka, laporan dan dokumen dari berbagai instansi yang terkait. Sedangkan data primer dalam kajian ini diperoleh melalui kegiatan survey lapangan dan responden pakar (pendapat ahli) melalui teknik kuesioner.

Menurut Nasution (2011) bahwa data primer adalah data yang diperoleh langsung dari sumbernya dan dicatat untuk pertama kali. Responden pakar terdiri atas 7 (tujuh) ahli/pakar. Menurut Hora (2004) menyebutkan bahwa jumlah expert yang memadai 3 hingga 6 atau 7 orang. Pakar ditentukan secara purposive sebanyak 7 orang responden dengan kriteria memiliki pengetahuan tentang obyek yang diteliti, mengetahui dengan baik lokasi 
penelitian, pendidikan minimal S2 yang terkait dengan pengetahuan yang dibutuhkan, berprofesi sebagai peneliti, pengajar, praktisi, dan pejabat pemerintah terkait.

\subsection{Analisis Data}

Metode analisis data yang digunakan dalam kajian model kelembagaan pengelolaan DAS-AF adalah teknik Intrepretative Structural Modelling (ISM). ISM merupakan suatu teknik berbasis komputer yang dapat membantu kelompok mengidentifikasi hubungan antara ide dengan struktur pada suatu isu yang kompleks, dimana bentuk proses metode ini adalah focus learning process. Menurut Saxena et al., (1992) bahwa teknik ISM bersangkut paut dengan interprestasi dari suatu objek yang utuh atau perwakilan sistem melalui aplikasi teori grafis secara sistematika dan interatif.

Penggunaan metode ISM juga telah luas digunakan, terutama untuk menganalisis struktural elemen-elemen berdasarkan hubungan kontekstualnya (Saxena et al., 1992; Machfud, 2001; Marimin, 2008). Metode ISM juga telah banyak digunakan dalam ilmu lingkungan, seperti untuk menentukan faktor kunci untuk meningkatkan kualitas air pada pengolahan air limbah industri makanan (Rimantho dan Rosdiana, 2018) dan penentuan aktor kunci pada pengelolaan DAS (Nuddin et al., 20017). Menurut Eriyatno (2012) menyebutkan bahwa metodologi atau teknik ISM dibagi menjadi dua bagian yaitu penyusunan hirarki dan klasifikasi sub-elemen. Prinsip dasarnya adalah identifikasi dari struktur didalam suatu sistem akan memberikan nilai manfaat yang tinggi guna meramu sistem secara efektif dan untuk pengambilan keputusan yang lebih baik. Lebih detil Attri et al., (2013) mengemukakan tahapan metodologi ISM, yaitu: (1) Structural Self-Interaction Matrix (SSIM); (2) Reachability matrix; (3) Level partitions; (4) Conical matrix; (5) Digraph; dan (6) ISM Model.

Tabel 1. Transformasi bentuk hubungan kontekstual antar elemen menjadi bentuk hubungan matematik

\begin{tabular}{cc}
\hline $\begin{array}{c}\text { Bentuk Hubungan } \\
\text { Kontekstual Antar Elemen } \mathbf{i} \\
\text { dan } \mathbf{j}(\mathrm{eij})\end{array}$ & $\begin{array}{c}\text { Bentuk Hubungan } \\
\text { Matematik Antar } \\
\text { Elemen } \mathbf{i} \text { dan } \mathbf{j} \text { (eij) }\end{array}$ \\
\hline V & Jika eij=1 dan eij=0 \\
A & Jika eij=0 dan eij=1 \\
X & Jika eij=1 dan eij=1 \\
O & Jika eij=0 dan eij=0 \\
\hline
\end{tabular}

Keterangan :

$\mathrm{V}$ : relasi dari elemen Ei sampai Ej, tetapi tidak berlaku untuk kebalikannya.

A : relasi dari elemen Ej sampai Ei, tetapi tidak berlaku untuk kebalikannya.

$\mathrm{X}$ : interrelasi antara Ei dan Ej (berlaku untuk kedua arah).

$\mathrm{O}$ : merepresentasikan bahwa Ei dan Ej adalah tidak berkaitan.

Tahapan pemodelan dengan teknik ISM adalah penentuan hubungan kontekstual yang kemudian dikonversi menjadi suatu hubungan matematik berupa reachibility matrix (RM). Hubungan antar elemen tersebut dinyatakan dalam perkalian Cartesian. Matrik harus memenuhi sifat reflexive dan transitive (Machfud, 2001). Dalam proses mentransformasi hubungan kontekstual (Matrik Structural Self-Interaction) menjadi bentuk hubungan matematik dalam bentuk matrik Reachability dengan aturan yang secara lengkap pada Tabel 1

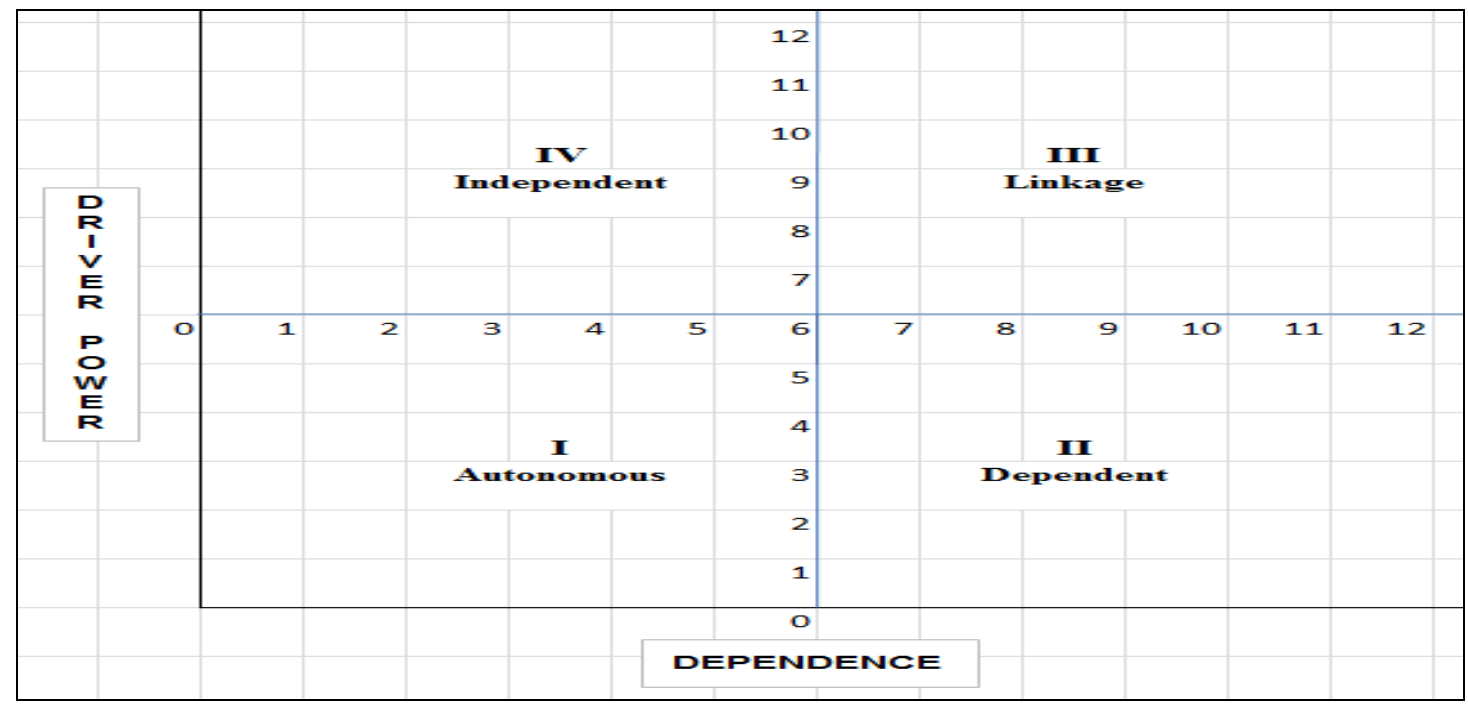

Gambar 1 Matrik Driver Power-Dependence dalam Teknik ISM (Marimin, 2008).

Menurut Eriyatno (1999) dan Kholil dkk. (2005), analisis terhadap model kelembagaan ini pada dasarnya untuk menyusun hirarki setiap sub elemen pada elemen yang dikaji, dan membuat klasifikasi kedalam 4 sektor, untuk menentukan sub elemen mana yang termasuk ke dalam variabel Autonomous 
(Sektor 1), Dependent (Sektor 2), Linkage (Sektor 3), atau Independent (Sektor 4). Secara grafik, kedudukan masing-masing sektor tersebut disajikan pada Gambar 1.

- Sektor 1: Weak Driver-Weak Dependent Variables (Autonomous) yang berarti bahwa sub elemen yang masuk dalam sektor ini umumnya tidak berkaitan dengan sistem dan mungkin mempunyai hubungan yang sedikit.

- Sektor 2: Weak Driver-Strongly Dependent Variables (Dependent) yang berarti bahwa sub elemen pada sektor ini adalah sub elemen yang tidak bebas.
- Sektor 3: Strong Driver-Strongly Dependent Variables (Linkage) yang berarti bahwa sub elemen yang masuk dalam sektor ini harus dikaji secara hati-hati karena hubungan antar sub elemen tidak stabil.

- Sektor 4: Strong Driver-Weak Dependent Variables (Independent) yang berarti bahwa sub elemen yang masuk dalam sektor ini merupakan bagian sisa dari sistem yang disebut dengan peubah bebas.

Berdasarkan hasil studi pustaka dan konsultasi pakar, diperoleh elemen dan sub elemen yang digunakan dalam kajian kelembagaan pengelolaan region DAS AF, seperti pada Tabel 2 .

Tabel 2. Elemen dan Sub Elemen dalam kajian Kelembagaan Pengelolaan DAS-AF

\begin{tabular}{|c|c|c|c|}
\hline No & Aktor / Pelaku & Kendala & Kebutuhan \\
\hline 1 & BPAS Benain Noelmina & $\begin{array}{llll}\text { Terbatasnya } & \text { Sarana } & \text { dan } & \text { prasarana } \\
\text { pendukung } & & & \end{array}$ & $\begin{array}{l}\text { Tata ruang yang tepat dan peningkatan sarana } \\
\text { /prasarana Pengelolaan DAS }\end{array}$ \\
\hline 2 & BWS NTT 2 & $\begin{array}{l}\text { rendahnya Kualitas, kuantitas, terutama } \\
\text { kontiunitas air bersih }\end{array}$ & $\begin{array}{l}\text { Penerapan teknologi KTA, Perluasan tutupan lahan dan } \\
\text { rehabilitas hutan dan lahan. }\end{array}$ \\
\hline 3 & FORDAS NTT & $\begin{array}{l}\text { Tingginya biaya PDAS berkelanjutan (tidak } \\
\text { ada DAK bidang DAS) }\end{array}$ & $\begin{array}{l}\text { Perlu alokasi khusus dana pengelolaan DAS dari APBN } \\
\text { maupun APBD }\end{array}$ \\
\hline 4 & BAPPEDA NTT & $\begin{array}{l}\text { SDM yang tidak memadai dan Kurangnya } \\
\text { kemampuan kapasitas institusi PDAS }\end{array}$ & $\begin{array}{l}\text { Resktrukturisasi dan peningkatan } \\
\text { kelembagaan dan SDM institusi PDAS }\end{array}$ \\
\hline 5 & Dinas PU NTT & $\begin{array}{l}\text { Lemahnya tatakelola kelembagaan dan } \\
\text { penggunaan system informasi dan aplikasi } \\
\text { teknologi PDAS }\end{array}$ & $\begin{array}{l}\text { Peningkatan kapasitas kelembagaan dan penggunaan } \\
\text { system informasi dan aplikasi teknologi pengelolaan DAS }\end{array}$ \\
\hline 6 & Akademisi/PT & $\begin{array}{l}\text { Menurunnya fungsi resapan air akibat } \\
\text { berkurangnya vegetasi pada daerah } \\
\text { tangkapan air }\end{array}$ & Peningkatan luas kawasan lindung dan tutupan lahan \\
\hline 7 & Masyarakat & $\begin{array}{l}\text { Rendahnya kesadaran masyarakat dan } \\
\text { dunia usaha dalam pengelolaan SDAL }\end{array}$ & $\begin{array}{l}\text { Peningkatan kesadaran dan pemberdayaan masyarakat } \\
\text { dan dunia usaha dalam PSDAL }\end{array}$ \\
\hline 8 & LSM & $\begin{array}{l}\text { Kurangnya koordinasi dan keterpaduan } \\
\text { PDAS antar stakeholders }\end{array}$ & $\begin{array}{l}\text { Peningkatan kapasitas koordinasi dan keterpaduan PDAS } \\
\text { antar stakeholders }\end{array}$ \\
\hline 9 & Bappeda Ngada & $\begin{array}{l}\text { Lemahnya pengawasan dan penegakan } \\
\text { hokum }\end{array}$ & Penegakan supermasi hokum dan Penyiapan RPDAS \\
\hline 10 & Bappeda Nagekeo & $\begin{array}{l}\text { Belum optimalnya upaya pengendalian } \\
\text { kekeringan dan banjir }\end{array}$ & Penangangan bahaya kekeringan dan banjir \\
\hline 11 & BLHD Ngada & $\begin{array}{l}\text { Belum adanya system insentif dan } \\
\text { disinsentif dalam PDAS }\end{array}$ & $\begin{array}{l}\text { Pemberian insentif dan disinsentif PDAS terutama terkait } \\
\text { pemnfaatan ruang }\end{array}$ \\
\hline 12 & BLHD Nagekeo & $\begin{array}{l}\text { Tidak adanya pembayaran atas jasa } \\
\text { lingkungan (PES) dalam PDAS }\end{array}$ & Pembayaran atas jasa lingkungan/PES PDAS. \\
\hline 13 & Dinas Pertanian Ngada & $\begin{array}{l}\text { Rendahnya pendapatan dan tingginya } \\
\text { angka kemiskinan }\end{array}$ & $\begin{array}{l}\text { Peningkatan pendapatan dan lapangan pekerjaan melalui } \\
\text { kegiatan budidaya dan pengolahan bamboo, agroforestri, } \\
\text { ekowisata dan geowisata. }\end{array}$ \\
\hline 14 & Dinas Pertanian Nagekeo & & \\
\hline 15 & Dinas Peternakan Ngada & & \\
\hline 16 & $\begin{array}{l}\text { Dinas } \\
\text { Nagekeo }\end{array}$ & & \\
\hline 17 & $\begin{array}{l}\text { Dinas Perikanan } \\
\text { Kelauatan NTT }\end{array}$ & & \\
\hline 18 & Organisasi Gereja & & \\
\hline
\end{tabular}

\section{Hasil dan Pembahasan}

Penelitian ini dilaksanakan di DAS Aesesa Flores pada Bulan April-Mei 2018. DAS Aesesa Flores (AF) secara geografis terletak pada posisi $120^{\circ} 56^{\prime} 48^{\prime \prime}$ 12122'42" BT dan 8029'01 LS - 8049'41" LS dan secara administrasi DAS Aesesa Flores ini masuk dalam dua wilayah administrasi kabupaten yang berada di Tengah Pulau Flores Provinsi NTT. Di region hulu dan sebagian kecil region tengah berada dalam wilayah administrasi Pemerintah Kabupaten Ngada dan region tengah dan hilir berada dalam wilayah administrasi Pemerintah Kabupaten Nagekeo. 
DAS AF merupakan salah satu DAS prioritas dengan luas $129.005 \mathrm{Ha}$ dan panjang $87 \mathrm{Km}$, serta terdapat 10 sub DAS dan menjadi kewenangan penanganan oleh Pemerintah Provinsi NTT dan BPDAS Benain Noelmina. Disamping itu pada region hulu ada kota Bajawa sebagai ibukota Kabupaten Ngada dan CA. Watu Ata sedangkan di region hilir ada kota Mbay sebagai ibukota Kabupaten Nagekeo, bendungan sutami dan area persawahan seluas 6.500 Ha (BPDAS BN 2013; Maan at al 2013; Noywuli 2017).

Ekosistem DAS AF terdiri dari tiga region (bagian/wilayah) yakni: 1) region hulu yang meliputi sebagian wilayah Kecamatan Bajawa, Golewa Selatan, Golewa, Bajawa Utara, Wolomeze dan Kecamatan Soa di Kabupaten Ngada; 2) region tengah yang meliputi sebagian wilayah Kecamatan Wolomeze di Kabupaten Ngada, Kecamatan Boawae dan sebagian wilayah Kecamatan Nangaroro di Kabupaten Nagekeo; dan 3) region hilir yang meliputi wilayah Kecamatan Aesesa, Aesesa Selatan dan 1 desa di Kecamatan Wolowae Kabupaten Nagekeo. Pewilayahan DAS AF selain didasarkan pada bentuk dan fungsi DAS, juga di dasarkan pada penggunaan dan tutupan vegetasi lahan, curah hujan, elevasi dan jumlah penduduk (Asdak, 2010). Region hulu berada pada titik koordinat 120 56'9.209"E, 847'39.959"S seluas 43.052 ha dengan elevasi antara 600 - 1.600 Mdpl . Region tengah berada pada titik koordinat 121 8'52.887"E, 841'25.092"S seluas 52.520 ha dengan elevasi antara 300 - $900 \mathrm{Mdpl}$. Sedangkan region hilir berada pada titik koordinat 121 17'57.719”E, 8 29'36.963"S seluas 33.433 ha dengan elevasi antara 25 - 300 Mdpl (BPDAS BN 2013; Noywuli 2017).

Salah satu aspek yang mempengaruhi kinerja pengelolaan DAS AF adalah aspek kelembagaan. Analisis kelembagaan yang dimaksudkan adalah untuk menggambarkan kondisi dan alternative institusi pengelola, norma dan peraturan yang berlaku, dan kendala serta kebutuhan dalam pengelolaan DAS AF (Hariadi at al 2004). Hasil analisis kelembagaan pengelolaan DAS AF dengan metode ISM disajikan menurut region yakni hulu, tengah dan hilir (Gambar 2-10). Berdasarkan hasil analisis kelembagaan pengelolaan DAS AF dari ketiga region diatas diperoleh bahwa aktor kunci dalam pengelolaan DAS-AF region hulu adalah a) BPDAS Benain Noelmina, b) BWS NTT 2, c) FORDAS NTT, d) Masyarakat, e) LSM, f) Bappeda Kab.Ngada, dan g) BLHD Kab.Ngada. Kedudukan dari aktor-aktor tersebut berada pada sektor III (Gambar 2A), sehingga dibutuhkan kehatian-hatian dalam pengkajiannya karena selain memiliki pengaruh yang besar juga memiliki tergantungan yang tinggi.

Kendala utama yang dihadapi dalam pengelolaan DAS-AF region hulu adalah a) Terbatasnya Sarana dan prasarana pendukung, b) Rendahnya Kualitas, kuantitas, terutama kontiunitas air bersih, c) Tingginya biaya PDAS berkelanjutan (tidak ada DAK bidang DAS), d) SDM yang tidak memadai dan Kurangnya kemampuan kapasitas institusi PDAS, e) Lemahnya tatakelola kelembagaan dan penggunaan system informasi dan aplikasi teknologi PDAS), f) Menurunnya fungsi resapan air akibat berkurangnya vegetasi pada daerah tangkapan air, g) Belum optimalnya upaya pengendalian kekeringan dan banjir, h) Belum adanya system insentif dan disinsentif dalam PDAS dan i) Rendahnya pendapatan dan tingginya angka kemiskinan). Kedudukan sub-elemen kendala tersebut kesemuanya berada pada sektor III (Gambar 3A), sehingga dibutuhkan kehatian-hatian dalam pengkajian dikarenakan setiap elemen kendala tersebut memiliki pengaruh dan ketergantungan yang tinggi.

Kebutuhan utama dalam pengelolaan DASAF region hulu adalah a) Terbatasnya Sarana dan prasarana pendukung, b) Rendahnya Kualitas, kuantitas, terutama kontiunitas air bersih, c) SDM yang tidak memadai dan Kurangnya kemampuan kapasitas institusi PDAS, d) Lemahnya tatakelola kelembagaan dan penggunaan system informasi dan aplikasi teknologi PDAS, e) Menurunnya fungsi resapan air akibat berkurangnya vegetasi pada daerah tangkapan air, f) Kurangnya koordinasi dan keterpaduan PDAS antar stakeholders, g) Lemahnya pengawasan dan penegakan hukum, h) Belum optimalnya upaya pengendalian kekeringan dan banjir, i) Belum adanya system insentif dan disinsentif dalam PDAS, j) Tidak adanya pembayaran atas jasa lingkungan (PES) dalam PDAS dan k) Rendahnya pendapatan dan tingginya angka kemiskinan. Kedudukan sub-elemen kebutuhan tersebut kesemuanya berada pada sektor III (Gambar 4A), sehingga dibutuhkan kehatian-hatian dalam pengkajian dikarenakan setiap elemen kebutuhan dalam pengelolaan DAS-AF tersebut memiliki pengaruh dan ketergantungan yang tinggi.Aktor kunci dalam pengelolaan DAS-AF region tengah adalah a) BPDAS Benain Noelmina, b) BWS NTT 2), c) FORDAS NTT, d) Masyarakat ), dan e) LSM. Kedudukan dari aktor-aktor tersebut berada pada sektor III (Gambar 5A), sehingga dibutuhkan kehatian-hatian dalam pengkajiannya karena selain memiliki pengaruh yang besar juga memiliki tergantungan yang tinggi.

Kendala utama yang dihadapi dalam pengelolaan DAS-AF region tengah adalah a) Terbatasnya Sarana dan prasarana pendukung, b) Rendahnya Kualitas, kuantitas, terutama kontiunitas air bersih, c) Tingginya biaya PDAS berkelanjutan (tidak ada DAK bidang DAS, d) SDM yang tidak memadai dan Kurangnya kemampuan kapasitas institusi PDAS, e) Lemahnya tatakelola kelembagaan dan penggunaan system informasi dan aplikasi teknologi PDAS), f) Menurunnya fungsi resapan air akibat berkurangnya vegetasi pada daerah tangkapan air), g) Belum optimalnya upaya pengendalian kekeringan dan banjir, h) Belum adanya system insentif dan disinsentif dalam PDAS dan i) Rendahnya pendapatan dan tingginya angka kemiskinan. Kedudukan sub-elemen kendala tersebut kesemuanya berada pada sektor III (Gambar 6A), sehingga dibutuhkan kehatian-hatian dalam 
pengkajian dikarenakan setiap elemen kendala tersebut memiliki pengaruh dan ketergantungan yang tinggi.

Kebutuhan utama dalam pengelolaan DASAF region tengah adalah a) Terbatasnya Sarana dan prasarana pendukung, b) Rendahnya Kualitas, kuantitas, terutama kontiunitas air bersih, c) Tingginya biaya PDAS berkelanjutan (tidak ada DAK bidang DAS), d) SDM yang tidak memadai dan Kurangnya kemampuan kapasitas institusi PDAS, e) Lemahnya tatakelola kelembagaan dan penggunaan system informasi dan aplikasi teknologi PDA), f)
Menurunnya fungsi resapan air akibat berkurangnya vegetasi pada daerah tangkapan air), g) Rendahnya kesadaran masyarakat dan dunia usaha dalam pengelolaan SDAL, h) Kurangnya koordinasi dan keterpaduan PDAS antar stakeholders, i) Belum optimalnya upaya pengendalian kekeringan dan banjir, j) Belum adanya system insentif dan disinsentif dalam PDAS, k) idak adanya pembayaran atas jasa lingkungan (PES) dalam PDAS) dan l) Rendahnya pendapatan dan tingginya angka kemiskinan.

\section{Kelembagaan Pengelolaan DAS-AF Region Hulu}

\section{A)}

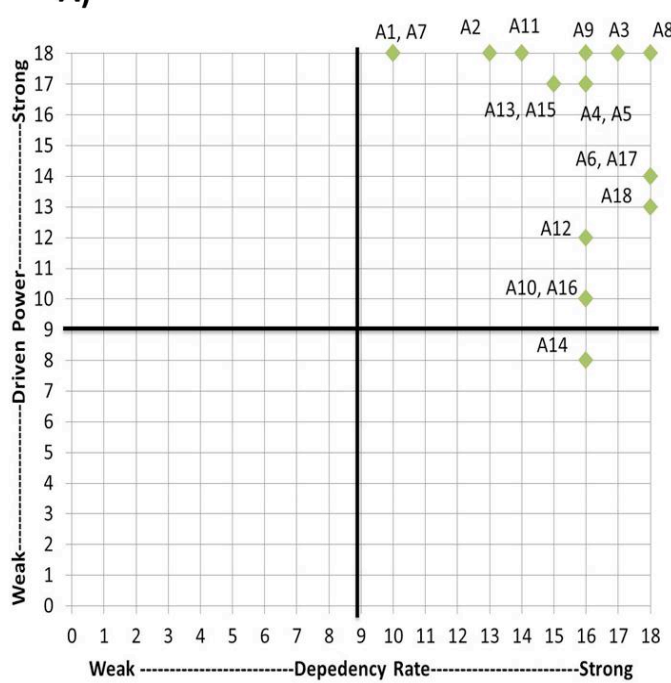

B)

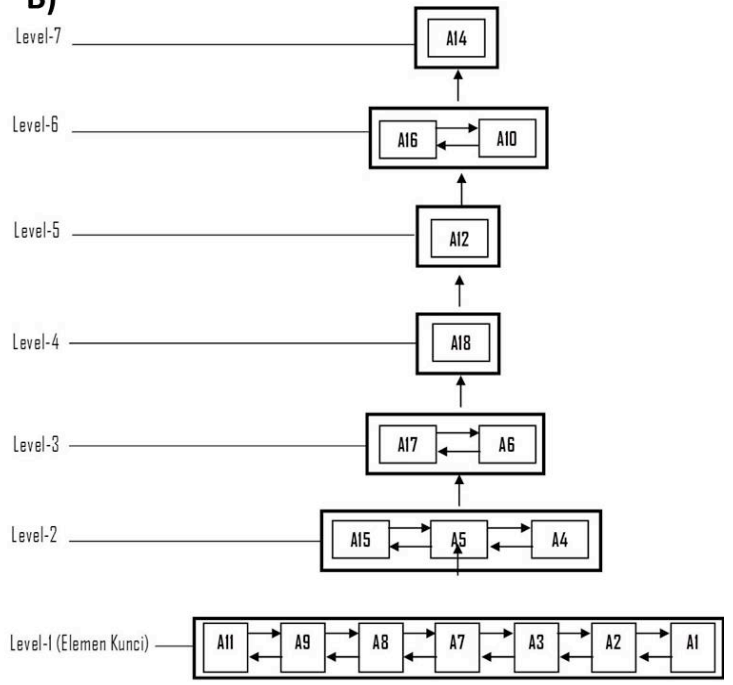

Gambar 2. A)Kedudukan sub-elemen aktor antara driver power-dependence; B)Struktur/Level Sub-Elemen Aktor dalam Pengelolaan DAS-AF Region Hulu

A)

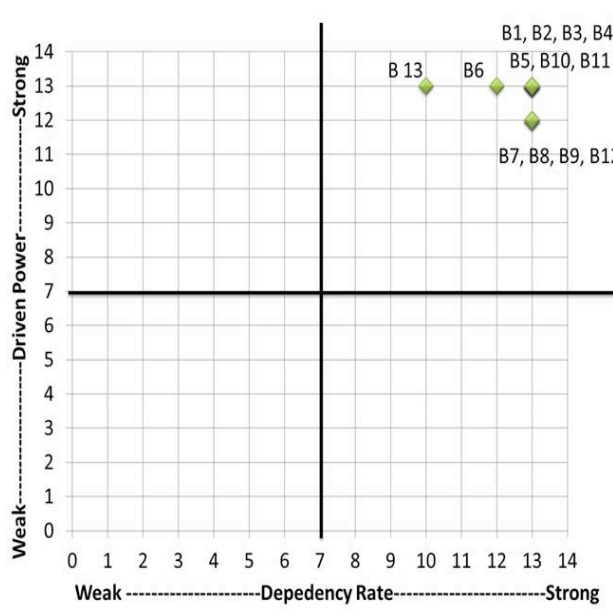

B)

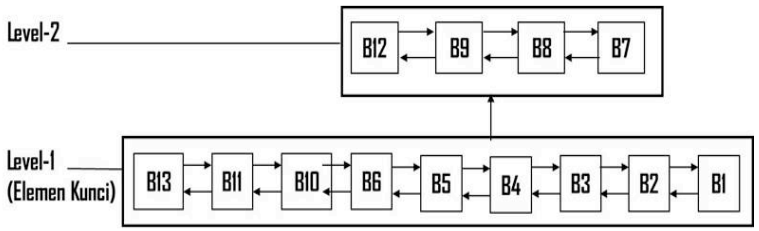

Gambar 3. A)Kedudukan sub-elemen kendala antara driver power-dependence ; B)Struktur/Level Sub-Elemen Kendala dalam Pengelolaan DAS-AF Region Hulu 
A)

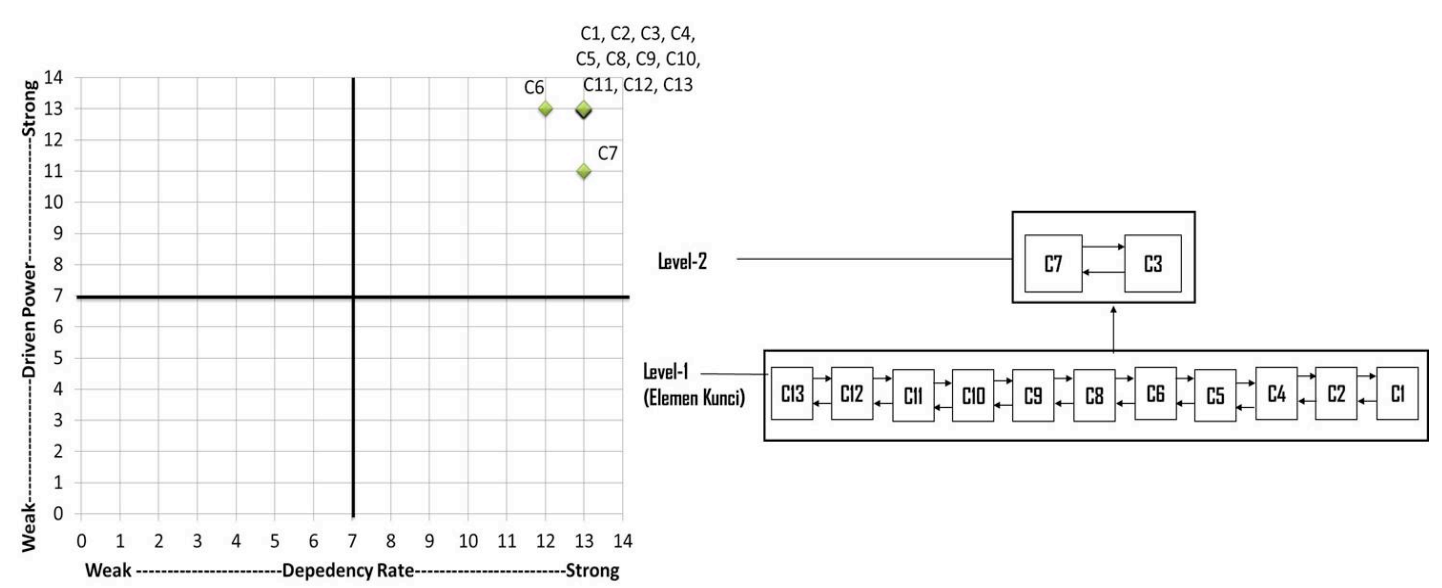

Gambar 4. A)Kedudukan sub-elemen kebutuhan antara driver power-dependence ; B)Struktur/Level Sub-Elemen Kebutuhan dalam Pengelolaan DAS-AF Region Hulu

\section{Kelembagaan Pengelolaan DAS-AF Region Tengah}

A)

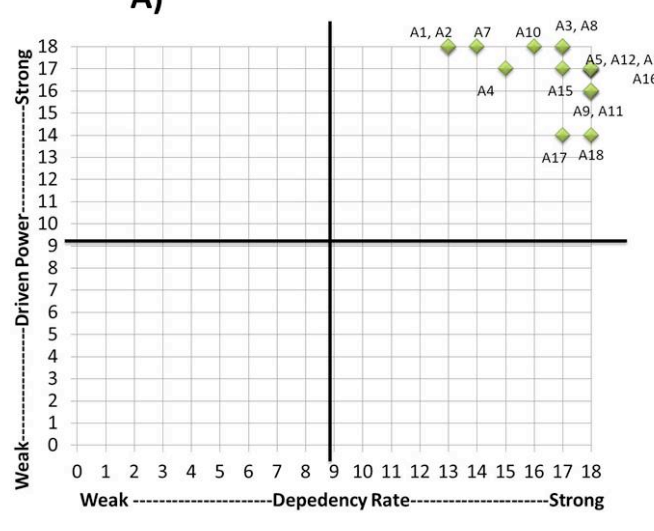

B)

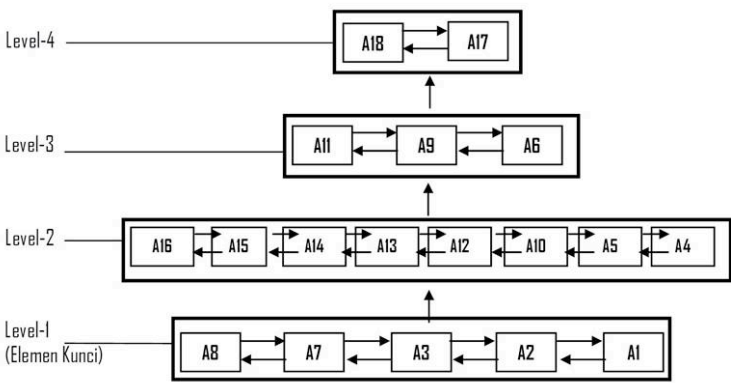

Gambar 5. A)Kedudukan sub-elemen aktor antara driver power-dependence; B)Struktur/Level Sub-Elemen Aktor dalam Pengelolaan DAS-AF Region Tengah

A)

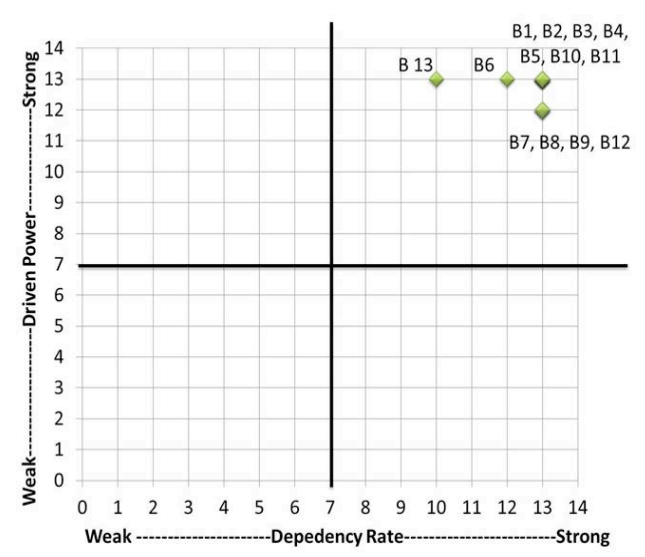

B)

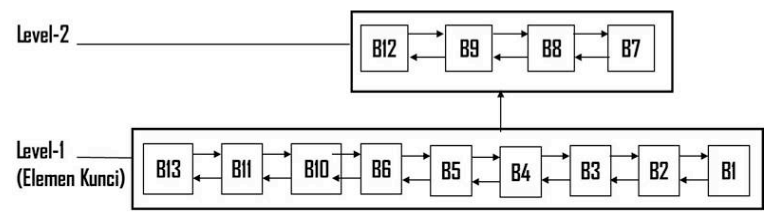

Gambar 6. A)Kedudukan sub-elemen kendala antara driver power-dependence ; B)Struktur/Level Sub-Elemen Kendala dalam Pengelolaan DAS-AF Region Tengah 
Noywuli, N., Sapei, A., Pandjaitan, N.H dan Eriyatno (2018). Model Kelembagaan Pengelolaan DAS Aesesa Flores, Provinsi NTT. Jurnal IImu Lingkungan, 16(2),136-146,

A)

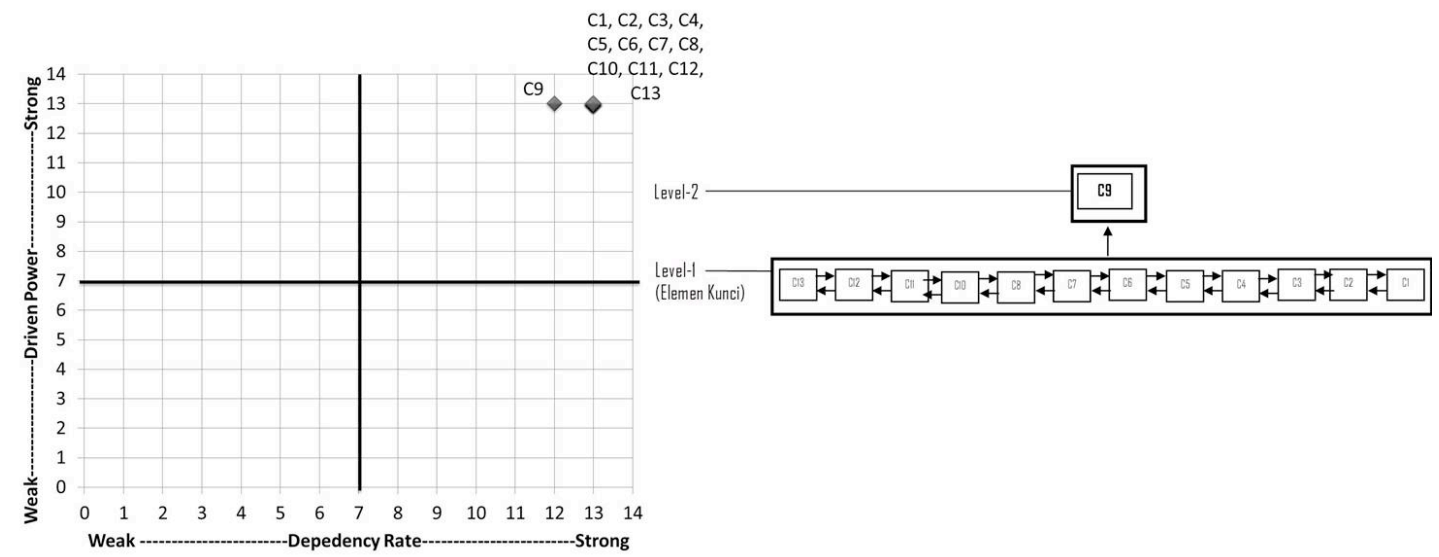

Gambar 7. A)Kedudukan sub-elemen kebutuhan antara driver power-dependence ; B)Struktur/Level Sub-Elemen Kebutuhan dalam Pengelolaan DAS-AF Region Tengah

\section{Kelembagaan Pengelolaan DAS-AF Region Hilir}

A)

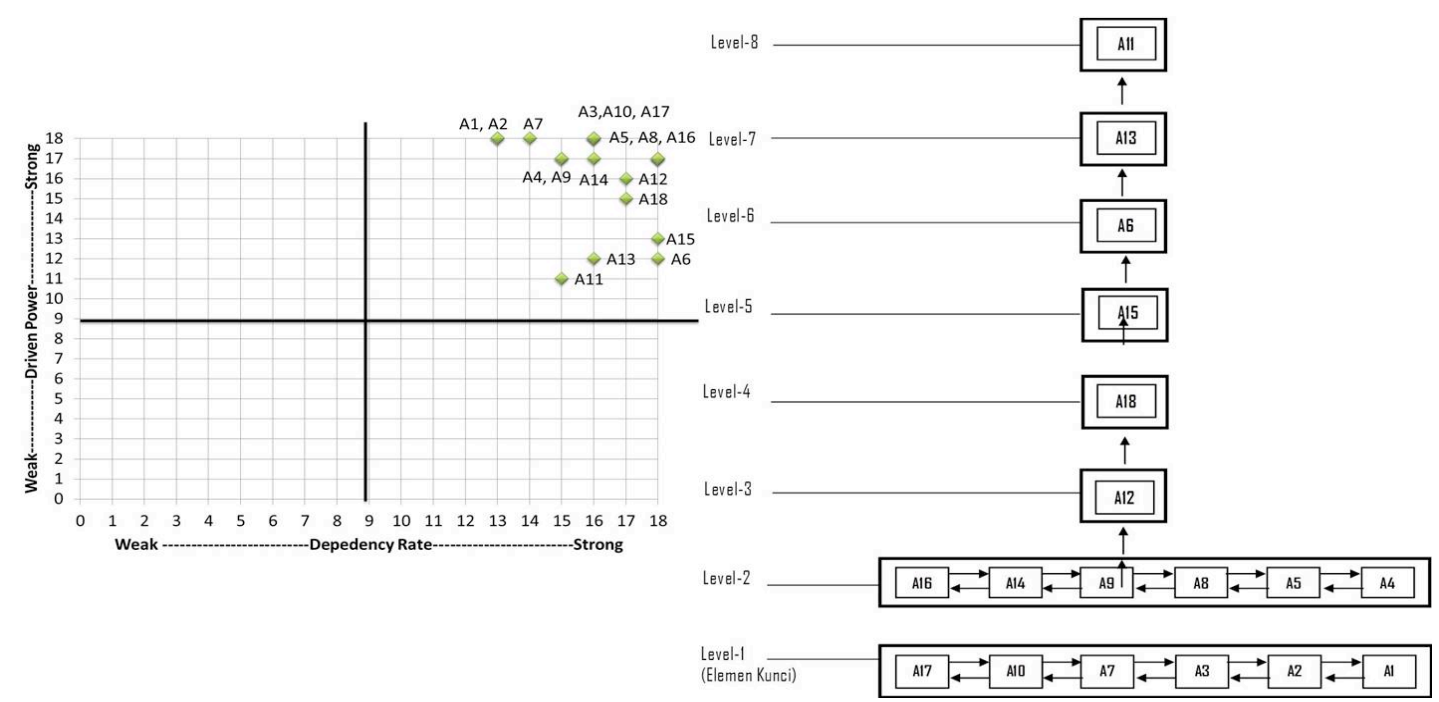

Gambar 8. A)Kedudukan sub-elemen aktor antara driver power-dependence ; B)Struktur/Level Sub-Elemen Aktor dalam Pengelolaan DAS-AF Region Hilir

A)

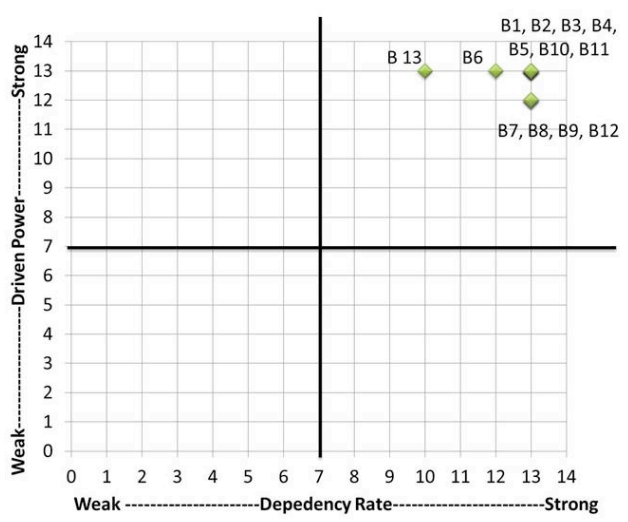

B)

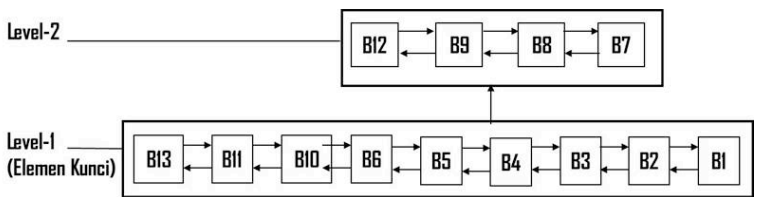

Gambar 9. A)Kedudukan sub-elemen kendala antara driver power-dependence ; B)Struktur/Level Sub-Elemen Kendala dalam Pengelolaan DAS-AF Region Hilir 


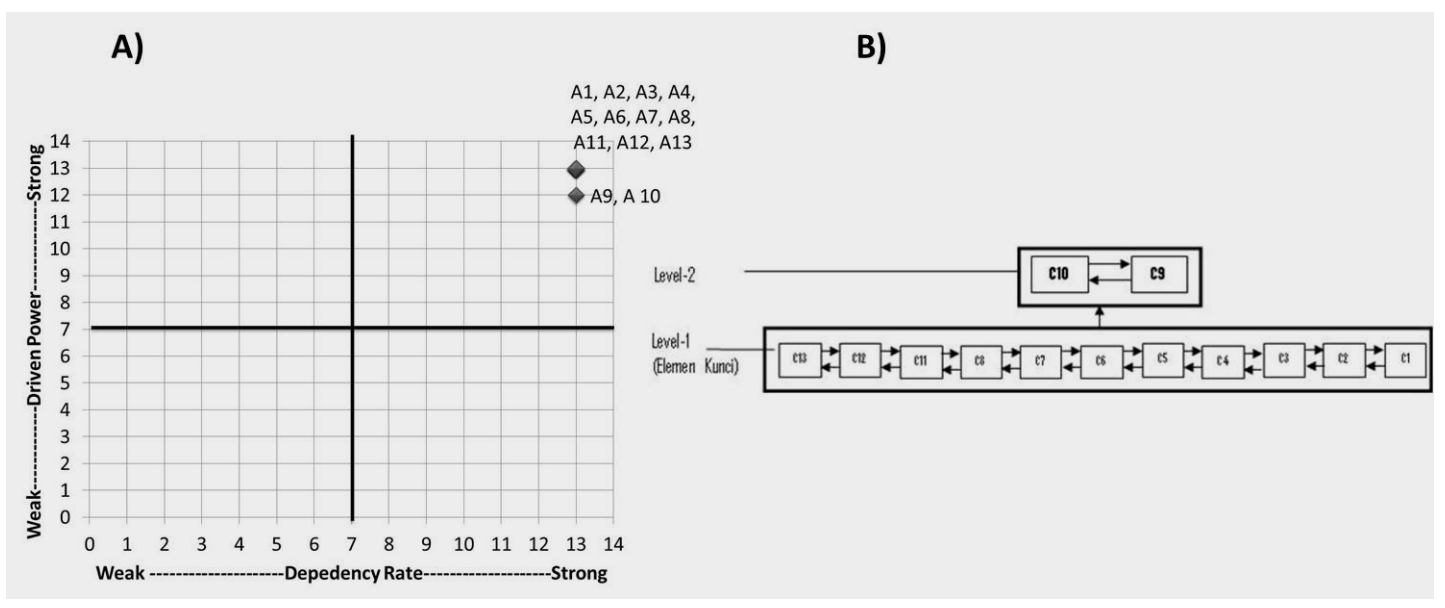

Gambar 10. A)Kedudukan sub-elemen kebutuhan antara driver power-dependence ; B)Struktur/Level Sub-Elemen Kebutuhan dalam Pengelolaan DAS-AF Region Hilir

Kedudukan sub-elemen kebutuhan tersebut kesemuanya berada pada sektor III (Gambar 7A), sehingga dibutuhkan kehatian-hatian dalam pengkajian dikarenakan setiap elemen kebutuhan dalam pengelolaan DAS-AF tersebut memiliki pengaruh dan ketergantungan yang tinggi.

Aktor kunci dalam pengelolaan DAS-AF region hilir adalah a) BPDAS Benain Noelmina, b) BWS NTT 2, c) FORDAS NTT, d) Masyarakat ), e) LSM), f) Bappeda Kab.Nagekeo), dan g) BLHD Kab.Nagekeo). Kedudukan dari aktor-aktor tersebut berada pada sektor III (Gambar 8A), sehingga dibutuhkan kehatian-hatian dalam pengkajiannya karena selain memiliki pengaruh yang besar juga memiliki tergantungan yang tinggi.

Kendala utama yang dihadapi dalam pengelolaan DAS-AF region hilir adalah a) Terbatasnya Sarana dan prasarana pendukung, b) Rendahnya Kualitas, kuantitas, terutama kontiunitas air bersih, c) Tingginya biaya PDAS berkelanjutan (tidak ada DAK bidang DAS), d) SDM yang tidak memadai dan Kurangnya kemampuan kapasitas institusi PDAS), e) Lemahnya tatakelola kelembagaan dan penggunaan system informasi dan aplikasi teknologi PDAS, f) Menurunnya fungsi resapan air akibat berkurangnya vegetasi pada daerah tangkapan air, g) Belum optimalnya upaya pengendalian kekeringan dan banjir, h) Belum adanya system insentif dan disinsentif dalam PDAS) dan i) Rendahnya pendapatan dan tingginya angka kemiskinan. Kedudukan sub-elemen kendala tersebut kesemuanya berada pada sektor III (Gambar 9A), sehingga dibutuhkan kehatian-hatian dalam pengkajian dikarenakan setiap elemen kendala tersebut memiliki pengaruh dan ketergantungan yang tinggi.

Kebutuhan utama dalam pengelolaan DAS-AF region hilir adalah a) Terbatasnya Sarana dan prasarana pendukung, b) Rendahnya Kualitas, kuantitas, terutama kontiunitas air bersih, c) Tingginya biaya PDAS berkelanjutan (tidak ada DAK bidang DAS), d) SDM yang tidak memadai dan Kurangnya kemampuan kapasitas institusi PDAS, e) Lemahnya tatakelola kelembagaan dan penggunaan system informasi dan aplikasi teknologi PDAS, f) Menurunnya fungsi resapan air akibat berkurangnya vegetasi pada daerah tangkapan air), g) Rendahnya kesadaran masyarakat dan dunia usaha dalam pengelolaan SDAL, h) Kurangnya koordinasi dan keterpaduan PDAS antar stakeholders, i) Belum adanya system insentif dan disinsentif dalam PDAS, j) Tidak adanya pembayaran atas jasa lingkungan (PES) dalam PDAS, dan k) Rendahnya pendapatan dan tingginya angka kemiskinan. Kedudukan sub-elemen kebutuhan tersebut kesemuanya berada pada sektor III (Gambar 10A), sehingga dibutuhkan kehatianhatian dalam pengkajian dikarenakan setiap elemen kebutuhan dalam pengelolaan DAS-AF tersebut memiliki pengaruh dan ketergantungan yang tinggi.

Keberhasilan pengelolaan DAS AF yang berkelanjutan dapat dilakukan dengan memperbaiki kendala utama dari masing-masing region yaitu a) Terbatasnya Sarana dan prasarana pendukung, b) Rendahnya Kualitas, kuantitas, terutama kontiunitas air bersih, c) Tingginya biaya PDAS berkelanjutan (tidak ada DAK bidang DAS), d) SDM yang tidak memadai dan Kurangnya kemampuan kapasitas institusi PDAS, e) Lemahnya tatakelola kelembagaan dan penggunaan system informasi dan aplikasi teknologi PDAS, f) Menurunnya fungsi resapan air akibat berkurangnya vegetasi pada daerah tangkapan air), g) Rendahnya kesadaran masyarakat dan dunia usaha dalam pengelolaan SDAL, h) Kurangnya koordinasi dan keterpaduan PDAS antar stakeholders, i) Belum adanya system insentif dan disinsentif dalam PDAS, j) Tidak adanya pembayaran atas jasa lingkungan (PES) dalam PDAS, dan k) Rendahnya pendapatan dan tingginya angka kemiskinan. Kendala ini perlu dicermati lebih serius karena cukup kompleks dan jika tidak segera diatasi maka DAS AF akan tidak berfungsi maksimal. 
Mengingat wilayah DAS AF berada pada dua wilayah administratif kabupaten yakni Ngada dan Nagekeo maka diperlukan koordinasi yang terintegrasi antar stakeholder dengan membuka peluang kerjasama antar pemerintah daerah. Serta menguatkan koordinasi diantara instansi terkait, yang dijabarkan dalam rencana aksi bersama SKPD di masing-masing daerah melalui RPJMD dan Renstra SKPD. Kebijakan bersama ini harus dilakukan karena tidak mungkin mengelola wilayah secara efektif dan efisien tanpa melihat konteks wilayah dan tanpa sinergi kerjasama yang dibangun diantara pemerintah daerah. Apabila koordinasi antar stakeholder dan pemerintah daerah yang terlibat dalam pengelolaan DAS AF yang berkelanjutan ini masih lemah dan tidak tercapai, maka akan akan berdampak langsung terhadap buruknya pengelolaan DAS AF. Hal ini akan menimbulkan permasalahan yang lebih kompleks di kemudian hari.

Penyusunan RTRW DAS AF dan dokumen DAS AF merupakan salah satu tools yang dapat digunakan sebagai media koordinasi dan kerjasama antar pemerintah pusat, pemerintah provinsi dan pemerintah daerah di wilayah penelitian. Institusi Pengelolaan DAS, BPDAS BN, BWS NTT 2 dan SKPD Instansi terkait di daerah merupakan aktor utama sekaligus pelaksana. Diperlukan kerjasama yang padu dan kompak antar stakeholder terkait untuk memaduserasikan rencana aksi serta programprogram yang berkaitan dengan pengelolaan DAS AF mengingat wilayah penelitian merupakan wilayah yang administratifnya dua kabupaten.

Dalam rangka mengurangi ketegangan dan konflik akibat benturan kepentingan, disaat permintaan (demand) tidak lagi seimbang dengan ketersediaan SDAL untuk pemenuhannya (supply). Diperlukan upaya secara proporsional dan seimbang antara pengembangan, pelestarian, dan pemanfaatan SDAL DAS AF baik dilihat dari aspek teknis maupun aspek hukum. Untuk memenuhi kebutuhan terus meningkat di berbagai sektor, diperlukan suatu perencanaan terpadu dan berkelanjutan yang berbasis DAS guna menentukan langkah dan tindakan yang harus dilakukan agar dapat memenuhi kebutuhan tersebut dengan mengoptimalkan potensi SDAL, melindungi/melestarikan serta meningkatkan nilai lahan maupun air. Sejalan dengan prinsip demokratis, masyarakat tidak hanya diberi peran dalam penyusunan rencana, pelaksanaan dan pengawasan pengelolaan DAS AF dan mengingat pengelolaan DAS AF merupakan masalah yang sangat kompleks dan melibatkan semua pihak sebagai pengguna, pemanfaat maupun pengelola, maka pengelolaan DAS AF yang berkelanjutan perlu dilakukan secara terpadu, komprehensif dan melibatkan seluruh stakeholder yang ada di DAS AF.

\section{Simpulan}

Pengelolaan DAS AF yang berkelanjutan masih menghadapi berbagai kendala. Kendala yang sama dihadapi dari ketiga region meliputi: a) Terbatasnya
Sarana dan prasarana pendukung, b) Rendahnya Kualitas, kuantitas, terutama kontiunitas air bersih, c) Tingginya biaya PDAS berkelanjutan (tidak ada DAK bidang DAS), d) SDM yang tidak memadai dan Kurangnya kemampuan kapasitas institusi PDAS), e) Lemahnya tatakelola kelembagaan dan penggunaan system informasi dan aplikasi teknologi PDAS, f) Menurunnya fungsi resapan air akibat berkurangnya vegetasi pada daerah tangkapan air, g) Belum optimalnya upaya pengendalian kekeringan dan banjir, h) Belum adanya system insentif dan disinsentif dalam PDAS) dan i) Rendahnya pendapatan dan tingginya angka kemiskinan. Kesembilan kendala dalam pengelolaan DAS AF, perlu segera diatasi agar pengelolaan DAS AF dapat berkelanjutan.

Program yang menjadi kebutuhan dalam pengelolaan berkelanjutan AF dari ketiga region adalah: a) Terbatasnya Sarana dan prasarana pendukung, b) Rendahnya Kualitas, kuantitas, terutama kontiunitas air bersih, c) Tingginya biaya PDAS berkelanjutan (tidak ada DAK bidang DAS), d) SDM yang tidak memadai dan Kurangnya kemampuan kapasitas institusi PDAS, e) Lemahnya tatakelola kelembagaan dan penggunaan system informasi dan aplikasi teknologi PDAS, f) Menurunnya fungsi resapan air akibat berkurangnya vegetasi pada daerah tangkapan air), g) Rendahnya kesadaran masyarakat dan dunia usaha dalam pengelolaan SDAL, h) Kurangnya koordinasi dan keterpaduan PDAS antar stakeholders, i) Belum adanya system insentif dan disinsentif dalam PDAS, j) Tidak adanya pembayaran atas jasa lingkungan (PES) dalam PDAS, dan k) Rendahnya pendapatan dan tingginya angka kemiskinan. Kesebelas sub elemen kebutuhan ini menjadi dasar pengelolaan DAS AF, sehingga perlu segera diimplementasikan dilapangan.

Aktor atau pelaku program pengelolaan DAS AF dari ketiga region yang sama dan paling berpengaruh adalah a) BPDAS Benain Noelmina, b) BWS NTT 2, c) FORDAS NTT, d) Masyarakat ), e) LSM). Ada tiga actor/lembaga yang berbeda dari ketiga region yakni untuk region hulu dan sebagian kecil tengah ditambah lembaga Bappeda Kab.Ngada dan BLHD Kab.Ngada, sedangkan untuk region hilir dan sebagian besar region tengah ditambah lembaga Bappeda dan BLHD Kabupaten Nagekeo. Terdapat 5 aktor/ lembaga sama dan dua lembaga yang berbeda yang terkait dan berpengaruh dalam pengelolaan DAS AF yang berkelanjutan, namun lembaga yang memiliki pengaruh paling besar dalam perumusan kebijakan pemerintah dalam hal pengelolaan DAS AF berkelanjutan yaitu BPDAS Benain Noelmina.

Sehingga disarankan perlu adanya kelembagaan khusus sesuai dengan karakteristik bigeofisik dan social ekonomi DAS AF atau di Pulau Flores pada umumnya untuk menangani pengelolaan DAS AF mengingat NTT adalah provinsi kepuluan dan banyaknya DAS di NTT dan menghadirkan Rencana Tata Ruang Wilayah DAS AF sebagai pedoman 
bersama. Disamping itu dperlukan sosialisasi dan penerapan serta pengendalian dari berbagai peraturan perundangan yang terkait langsung yakni PP 37 tahun 2013 tentang Pengelolaan DAS; Peraturan Pemerintah Provinsi NTT Nomor 5 tahun 2005 tentang Pengelolaan DAS Terpadu; dan Rencana Pengelolaan DAS Aesesa tahun 2013.

\section{DAFTAR PUSTAKA}

Baker, G.,Gibbons, R.,and Murphy, K.J. 1994. Subjective Peromance Measure in Optimal Incentive Contract. The Quarterly Journal of Economics, 109 (4): 11251156.

Cifuentes, M. 1992. Tourism Priciples and Practice. Longman Group. London

Direktorat Vulkanologi. 2003. Peta Kawasan Rawan Bencana. Direktorat Vulkanologi dan Mitigasi Bencana Geologi.

Dwikorawati, S,S. 2012. Model Kebijakan Pengelolaan Pariwisata Yang Berdaya Saing Dan Berkelanjutan Di Kawasan Puncak Kabupaten Bogor. IPB. Bogor

Fandeli, Chafid dan Muhammad. 2009. Prinsip-prinsip Dasar Mengkonservasi Lanskap. Gadjah Mada University Press. Yogyakarta

Fauzi. A. 2004. Ekonomi Sumber Daya Alam dan Lingkungan, Teori dan Aplikasi. PT. Gramedia Pustaka Utama. Jakarta

Kavanagh. 2001. Rapid Appraisal of Fisheries (Rapfish) Project. Rapfish Software Description (For Micrisoft Exel). University of British Columbia. 80p

Kavanagh, P., Pitcher, T.J., 2004. Implementing Microsoft Excel Software for Rapfish : A Technique for the Rapid Appraisal of Fisheries Status. Fisheries Centre Research Reports 12 (2), 75 p.

Keputusan Presiden Nomor 32 tahun 1990 tentang Pengelolaan Kawasan Lindung. Jakarta

Mathieson A, Wall G, 1982. Tourism: Economic, Physical and Social Impacts. New York : Longman.

Munasinghe, M. 1993, Environmental Economic and Sustainable Development The International bank for Recontruction and Development. World Bank Washington. USA.

Pitana dan Diarta, 2009. Pengantar Ilmu Pariwisata. Penerbit ANDI Yogyakarta.

Santoso, M.A. 2001, Good Governance Hukum Lingkungan. Jakarta ICEL dalam Lewaherilla N.E. 2006. Analisis Kebijakan Pengelolaan Kawasan Taman Wisata Teluk Youtefa-Jayapura.

Sugandhy A. 1999. Penataan Ruang dalam Pengelolaan Lingkungan Hidup. Gramedia Pustaka Utama. Jakarta.

Undang-Undang Negara RI Nomor 26 Tahun 2007 tentang Penataan Ruang. Jakarta.

Undang-undang Republik Indonesia Nomor 10 Tahun 2009 tentang Kepariwisataan

Wahab. 1992. Manajemen Kepariwisataan. Penerbit Pradnya Paramita. Jakarta

Wisner. 2004. Principles of Supply Chain Management, A Balance Approach. Thomson

[WTO] World Tourism Organization, 1995. Sustainable Tourism Development: Guide for Planners. World Tourism Organization. Spain.

Yoeti, 0. 1988. Pengantar Ilmu Parawisata. Angkasa Bandung. Bandung

Kinetics. Hindawi Publishing Corporation, BioMed Research International Article ID134872, II pages. 